\title{
A Prospective Evaluation of Preoperative Screening Laboratory Tests in General Surgery Patients
}

\author{
Basel M. Alsumait ${ }^{a}$ Salah A. Alhumood c Titiana Ivanova $^{b}$ Maher Mores $^{a}$ \\ Magdi Edeia ${ }^{a}$
}

Departments of a Surgery, ${ }^{\mathrm{b}}$ Anesthesia, and ${ }^{\mathrm{C}}$ Laboratory Medicine, Mubarak Al-Kabeer Hospital, Kuwait

\section{Key Words}

Preoperative care $\cdot$ Laboratory tests $\cdot$ Hospital

\begin{abstract}
Objective: To assess the value of routine biochemical and hematological screening of otherwise healthy patients prior to elective general surgery. Materials and Methods: Prospective laboratory screening tests were done for 1,000 consecutive patients undergoing elective general surgery at Mubarak Al-Kabeer Hospital, Kuwait, from January to August 1999. Patients with abnormal laboratory results were interviewed and examined preoperatively as part of the present study protocol, to identify a possible cause for the abnormal laboratory result. The perioperative course of these patients was also monitored. Results: Approximately $14 \%$ of the preoperative tests were abnormal, $9.2 \%$ of which was expected while $4.9 \%$ was unexpected; there was no change in the preoperative care of patients with unexpected abnormalities, nor was there surgical delay or related postoperative complication. Conclusion: The results indicate that laboratory tests should be selectively used when the patient has appropriate risk factors. Instead, greater emphasis should be placed on history and physical examination. Application of such policy will result in substantial financial savings that could be utilized to improve the health
\end{abstract} care system.

Copyright $@ 2002$ S. Karger AG, Basel

\section{Introduction}

Cost containment in medicine has led to the reevaluation of many routine time-honored investigations. Traditionally accepted screening preoperative tests have been the subject of close scrutiny [1-6]. Recently, Schein et al. [1], in a prospective study including 19,557 patients for elective cataract surgery, have shown that blood testing before surgery does not increase the safety of surgery. Although numerous other studies have demonstrated that a routine preoperative battery of tests are not necessary for asymptomatic patients, these tests are still routinely done in Kuwait hospitals. Although the cost of each individual test is low (ranging from US \$10 to \$20), the aggregate costs can be substantial. In this study, we prospectively assessed the value of routine preoperative laboratory tests in patients undergoing general surgery at Mubarak Al-Kabeer Hospital, Kuwait.

\section{Method}

Of the 3,367 general surgical cases (elective and emergency) performed during the year 1999 at Mubarak Al-Kabeer Hospital, Kuwait, we prospectively studied laboratory screening tests for 1,000 consecutive elective general surgical admissions from January to August 1999. The following preoperative laboratory tests were routinely done on all the patients: electrolytes (sodium, potassium), carbon dioxide, glucose, renal profile (urea, creatinine), complete blood

\begin{tabular}{ll}
\hline KARGER & ( ) 2002 S. Karger AG, Basel \\
Fax +4161306 1234 & \\
$\begin{array}{l}\text { E-Mail karger@karger.ch } \\
\text { www.karger.com }\end{array}$ & $\begin{array}{l}\text { Accessible online at: } \\
\text { www.karger.com/journals/mpp }\end{array}$
\end{tabular}

Basel Alsumait

PO Box 441

45705 Alsurrah (Kuwait)

Tel. +965 5310304

E-Mailbalsumait@hotmail.com 
Table 1. Summary of preoperative laboratory results

\begin{tabular}{|c|c|c|c|c|c|c|c|c|}
\hline Test & $\begin{array}{l}\text { Serum } \\
\text { glucose }\end{array}$ & $\begin{array}{l}\text { Serum creatinine } \\
\text { and urea }\end{array}$ & Serum $\mathrm{Na}^{+}$ & Serum $\mathrm{K}^{+}$ & Plasma INR & Plasma PTT & Blood platelets & Total \\
\hline $\begin{array}{l}\text { Reference } \\
\text { range }\end{array}$ & $\begin{array}{l}3.9-6.1 \\
\mathrm{mmol} / \mathrm{l}\end{array}$ & $\begin{array}{l}\text { serum creatinine } \\
60-120 \mu \mathrm{mol} / 1 \\
\text { serum urea } \\
2.5-5.6 \mathrm{mmol} / 1\end{array}$ & $\begin{array}{l}135-148 \\
\mathrm{mmol} / 1\end{array}$ & $\begin{array}{l}3.5-5.3 \\
\mathrm{mmol} / 1\end{array}$ & up to 1.2 & up to $42 \mathrm{~s}$ & $130-400 \times 10^{9} / 1$ & \\
\hline Abnormal tests & $82(8.2 \%)$ & $16(1.6 \%)$ & $2(0.2 \%)$ & $4(0.4 \%)$ & $14(1.4 \%)$ & $12(1.2 \%)$ & $11(1.1 \%)$ & $141(14.10 \%)$ \\
\hline $\begin{array}{l}\text { Expected } \\
\text { abnormalities }\end{array}$ & $50(5 \%)$ & $11(1.1 \%)$ & $2(0.2 \%)$ & $3(0.3 \%)$ & $11(1.1 \%)$ & $6(0.6 \%)$ & $9(0.9 \%)$ & $92(9.20 \%)$ \\
\hline $\begin{array}{l}\text { Etiology of } \\
\text { expected } \\
\text { abnormalities }\end{array}$ & $\begin{array}{l}49 \text { diabetes, } \\
1 \text { pancreatic } \\
\text { cancer }\end{array}$ & $11 \mathrm{CRF}$ & $\begin{array}{l}1 \text { diarrhea }^{\mathrm{a}} \text {, } \\
1 \mathrm{CRF}\end{array}$ & $3 \mathrm{CRF}$ & $\begin{array}{l}4 \text { cirrhosis, } 5 \text { anti- } \\
\text { coagulation treat- } \\
\text { ment, } 1 \text { liver me- } \\
\text { tastases, } 1 \text { HHA }\end{array}$ & $\begin{array}{l}3 \text { cirrhosis, } \\
3 \text { anticoagulation } \\
\text { treatment }\end{array}$ & $\begin{array}{l}4 \text { ITP, } 4 \text { cirrhosis, } \\
1 \text { massive blood } \\
\text { transfusion }^{\text {b }}\end{array}$ & \\
\hline $\begin{array}{l}\text { Unexpected } \\
\text { abnormalities }\end{array}$ & $32(3.2 \%)$ & $5(0.5 \%)$ & 0 & $1(0.1 \%)$ & $3(0.3 \%)$ & $6(0.6 \%)$ & $2(0.2 \%)$ & $49(4.90 \%)$ \\
\hline
\end{tabular}

There was no active intervention or surgery delay due to unexpected abnormalities.

$\mathrm{CRF}=\mathrm{Chronic}$ renal failure; HHA = hereditary hemolytic anemia; ITP = idiopathic thrombocytopenic purpura.

a Ulcerative colitis with diarrhea causing dehydration.

b Patient had packing for severe liver trauma and was taken to the operating room for semielective unpacking.

count $(\mathrm{CBC})$ including platelet count, and coagulation profile [prothrombin time international ratio (PT-INR) and partial thromboplastin time (PTT)]. Hemoglobin level was not done because, in addition to patients with clinically suspected anemia, we routinely obtain hemoglobin level from patients in all surgeries with expected significant blood loss, patients above 40 years of age, and from all females and infants below the age of 6 months. This policy was based on extensive reviews of the literature in this field [7, 8]. Patients who were found to have an abnormal result were interviewed and examined preoperatively to try to identify a possible cause for the abnormal laboratory test. We also monitored the surgeon and anesthetist involved in both the pre- and postoperative management of the patient to assess whether or not the abnormality had any effect on the patient's management.

Blood specimens for preoperative tests were collected either on the day of admission prior to the surgery, or within 1 month prior to the scheduled date of surgery. Patients with certain medical problems had some tests repeated in the immediate preoperative period; for example, serum glucose for diabetics, serum potassium and sodium for patients with renal failure and coagulation profile for patients on anticoagulation treatment. Patients were instructed to fast for the blood tests. Electrolyte and renal profiles were performed on an automated analyzer (Beckman LX20) with dedicated reagents supplied by Beckman Instruments (Beckman Instruments, Brea, Calif., USA). Coagulation screen was performed using ACL-2000 system (Instrumentation Laboratory, Ill., USA), which is a fully automated microcomputer analyzer that is based on an optical density detection system. Reagents were also supplied by Instrumentation Laboratory. $\mathrm{CBC}$ was performed on Gen-S (Beckman Coulter), a fully automated blood cell analyzer.

\section{Results}

One hundred and thirty-seven patients were found to have 141 abnormal preoperative results. Table 1 shows the details of these abnormalities including reference ranges as determined in our laboratory from a population of healthy individuals. These reference ranges were calculated from arithmetic mean $\pm 2 \mathrm{SD}$. However, clinically critical values were defined based on data in the literature. While $65 \%$ of these abnormalities were expected preoperatively as a result of a preexisting disease process, $35 \%$ of them were not.

Patients ranged in age from 12 to 90 years; $25 \%$ of the patients with an abnormal test result were below the age of 40. The operative procedures performed on the study patients were categorized as follows: $36 \%$ major operations, $26 \%$ intermediate and $38 \%$ minor operations. The operative procedures performed on patients with unexpected abnormalities were as follows: $40 \%$ major, $24 \%$ intermediate and $36 \%$ minor.

Glucose. While $3.2 \%$ of the study patients had unexpected high serum glucose, the maximum serum glucose level in this group was $9 \mathrm{mmol} / \mathrm{l}$. No preoperative interventions were made and there were no surgical delays in this group of patients. No patient was found to have unexpected low serum glucose level.

Potassium. The only unexpected abnormality was in a 30 -year-old patient with a potassium level of $3.31 \mathrm{mmol} / \mathrm{l}$; 
this is a mild, not surgically significant abnormality. No preoperative intervention was made to elevate the potassium level by the attending surgeon or the anesthetist, and no problem was recorded in the perioperative course that was related to the low potassium level.

Renal Profile. Of the 5 unexpected abnormalities seen, 4 patients had a normal serum creatinine and a raised serum urea level (maximum urea level was $7.7 \mathrm{mmol} / \mathrm{l}$ ); these were mild, and not surgically significant abnormalities. The 5th patient was 74 years old with serum creatinine and urea levels of $146 \mu \mathrm{mol} / \mathrm{l}$ and $11 \mathrm{mmol} / \mathrm{l}$, respectively. There was no change in the management of this patient by the surgeon or anesthetist related to this abnormality, and no related perioperative complication was recorded.

Platelets. Two patients had unexpected low platelet counts of 98 and $95 \times 10^{9} / 1$, respectively.

$P T T$. The 6 unexpected abnormalities ranged between 44 and $55 \mathrm{~s}$. These abnormalities were considered relatively mild, and no preoperative attempt was made to correct the high PTT. No bleeding tendency was recorded in this group of patients.

$P T-I N R$. The 3 unexpected abnormalities ranged between an INR level of 1.3 and 1.4; no preoperative attempt was made to correct the high PT level and no bleeding complication was recorded.

\section{Discussion}

In this study, $14.1 \%$ of preoperative tests were abnormal; of these $9.2 \%$ were expected from the history and physical examinations done preoperatively, and 4.9\% were not. However, no alteration in the preoperative care was recorded in any of the patients with unexpected abnormalities. There was no surgical delay and postoperatively, no related complications were recorded in this group of patients. The maximum serum glucose level in patients with unexpected abnormalities was $9 \mathrm{mmol} / \mathrm{l}$, and studies have shown that the average preoperative serum glucose level goal preoperatively in known diabetics should be between 11.1 and $13.9 \mathrm{mmol} / 1$ [4, 5]. Unexpected platelet abnormalities were above $90 \times 10^{9} / 1$, and, in general, platelet counts above $50 \times 10^{9} / 1$ are not usually considered significant for surgical procedures $[6,7]$. Unexpected abnormalities in PTT were considered relatively mild, and, in general, not all patients with a prolonged PTT have a bleeding tendency. For example, patients with lupus anticoagulant and those with contact factor deficiency, such as factor xii, do not have a bleeding tendency in spite of a prolonged PTT $[6,7]$. The maximum number of unexpected abnormalities in INR was 1.4 , and, in general, an INR level less than 1.5 is acceptable for elective general surgical procedures [11-13].

These results indicate that a large portion of preoperative laboratory tests can be eliminated without significant adverse medical consequences and that testing should be done only for specific indications. This proposition, however, places the burden on the history taker; the physician must determine if the patient's health is optimal, and therefore, fit for surgery. This important decision might be wrong if there are obstacles to the process of proper history taking, such as lack of time, language barrier, or an inexperienced anesthetist. These problems can be solved only by the joint efforts of surgeons, anesthetists and administration. The ideal setup would involve the creation of preoperative assessment clinics run by qualified senior anesthetists, and a well-designed questionnaire would help in avoiding inefficient preoperative assessment.

Several studies [2-6] have shown that there is not much benefit from preoperative laboratory testing. Kaplan et al. [2], McKee and Scott [3], Hackmann et al. [4], Nigam et al. [5], and Baron et al. [6], all showed that no management changes were recorded in all of the patients with unexpected abnormal test results; these five studies collectively involved 8,341 patients.

Abnormalities in asymptomatic patients may not reflect the presence of disease. For tests reported as continuous results, the distribution of the results in a population of patients is Gaussian (i.e. normal); the values defining 'abnormal' are set arbitrarily, so that test results exceeding those of the highest $2.5 \%$ of health individuals or falling below those of the lowest $2.5 \%$ of healthy individuals are said to be abnormal. The test results between these two extremes are 'within the reference range'; therefore $5 \%$ of test results from patients without disease will be 'outside the hospital reference range'.

Laboratory tests that are not warranted by the medical history of a patient do not provide medicolegal protection against liability [2]. Studies have shown that 30-95\% of all unexpected abnormalities found on preoperative laboratory tests are not noted on the chart before surgery [2, 14, 15-17]. Failure to pursue an abnormality appropriately poses a greater risk of medicolegal liability than does failure to detect that abnormality [17].

In our institution approximately 2,000 elective general surgical operations are performed annually. According to an internal document of the Finance Department, Ministry of Health, Kuwait, the cost of some of the preoperative 
tests, in Kuwaiti Dinars (KD) in the year 1999, is as follows: CBC costs KD 3.000 (US \$10.00), PT and INR cost KD 3.000 (US \$10.00), PTT costs KD 3.000 (US \$10.00), and biochemical profile costs KD 6.000 (US \$20.00). Therefore, the collective cost of these preoperative tests for the elective general surgical cases was approximately KD 30,000 (US \$100,000). If preoperative testing is not carried out in asymptomatic healthy preoperative patients, and if we include the many other ministry hospitals in our calculations, the financial savings would be substantial. With increasing costs of health care delivery, more selective policies for utilization of medical resources will be required. Narr et al. [18] of the Mayo Clinic reported the evaluation of their policy of not performing routine preoperative screening tests for healthy patients younger than the age of 40 since 1990 . He found no patient with perioperative morbidity that could have been prevented by preoperative laboratory tests.

\section{Conclusion}

Laboratory tests should be used selectively when a patient has the appropriate risk factors. Routine preoperative laboratory tests are not cost-effective and do not provide medicolegal protection against liability. In the screening of preoperative patients for disease, greater emphasis should be placed upon the history and physical examination.

\section{References}

1 Schein OD, Katz J, Bass EB, Tielsch JM, Lubomski LH, Feldman MA, Petty BG, Steinberg EP: The value of routine preoperative medical testing before cataract surgery. N Engl $\mathrm{J}$ Med 2000;342;168-175.

2 Kaplan EB, Sheiner LB, Boeckmann AJ, Roizen MF, Beal SL, Cohen SN, Nicell CD: The usefulness of preoperative laboratory screening. JAMA 1985;253:3576-3581.

3 McKee RF, Scott EM: The value of routine preoperative investigations. Ann R Coll Surg Engl 1987;69:160-162.

4 Hackmann T, Seward DJ, Sheps SB: Anemia in pediatric day-surgery patients: Prevalence and detection. Anesthesiology 1991;75:27-31.

5 Nigam A, Ahmed K, Drake-Lee AB: The value of preoperative estimation of haemoglobin in children undergoing tonsillectomy. Clin Otolaryngol 1990;15:549-551.

6 Baron MJ, Gunter J, White P: Is the pediatric preoperative hematocrit determination necessary? South Med J 1992;85:1187-1189.
7 Dullman PR, Yip R, Johnson C: Prevalence and cause of anemia in the United States. Am J Clin Nutr 1984;39;437-445.

8 Berwich DM: Screening in health fair. JAMA 1985;254:1492-1498.

9 Schade DS: Surgery and diabetes. Med Clin North Am 1988;72:1531-1543.

10 Fetchick DA, Fischer JS: Preoperative management of the patient with diabetes mellitus undergoing outpatient or elective surgery. Clin Podiatr Med Surg 1987;4:439-443.

11 Rohrer MJ, Michelotti MC, Nahrwold DL: A prospective evalution of the efficacy of preoperative coagulation testing. Ann Surg 1988; 208:554-557.

12 Houry S, Georgeac C, Hay JM, Fingerhut A, Boudet MJ: A prospective multicenter evaluation of preoperative hemostatic screening tests. The French Associations for Surgical Research. Am J Surg 1995;170:19-23.
13 Sridhar R: The preoperative management of anticoagulation. Aust Prescriber 2000;23:1316.

14 Wolf-Klein GP, Holt T, Silverstone FA, Foley CJ, Spatz M: Efficacy of routine annual studies in the care of elderly patients. J Am Geriatr Soc 1985;33:325-329.

15 Wood RA, Hoekelman RA: Value of the chest $\mathrm{X}$-ray as a screening test for elective surgery in children. Pediatrics 1981;67:447-452.

16 Rabkin SW, Horne JM: Preoperative electrocardiography: Its cost effectiveness in detecting abnormalities when a previous tracing exists. Can Med Assoc J 1979;121:301-306.

17 Rabkin SW, Horne JM: Preoperative electrocardiography: Effects of new abnormalities on clinical decisions. Can Med Assoc J 1983;128: 146-147.

18 Narr BJ, Warner ME, Schroeder DR, Warner MA: Outcomes of patients with no laboratory assessment before anesthesia and a surgical procedure. Mayo Clin Proc 1997;72:505-509. 